\title{
Trends of imported malaria in China 2010-2014: analysis of surveillance data
}

Sheng Zhou ${ }^{1 \dagger}$, Zhongjie $\mathrm{Li}^{1 \dagger}$, Chris Cotter ${ }^{2}$, Canjun Zheng ${ }^{1}$, Qian Zhang ${ }^{1}$, Huazhong Li ${ }^{1}$, Shuisen Zhou ${ }^{3}$, Xiaonong Zhou ${ }^{3}$, Hongjie Yu ${ }^{1 *}$ and Weizhong Yang ${ }^{1 *}$

\begin{abstract}
Background: To describe the epidemiologic profile and trends of imported malaria, and to identify the populations at risk of malaria in China during 2010-2014.

Methods: This is a descriptive analysis of laboratory confirmed malaria cases during 2010-2014. Data were obtained from surveillance reports in the China Information System for Disease Control and Prevention (CISDCP). The distribution of imported malaria cases over the years was analysed with $X^{2}$ for trend analysis test. All important demographic and epidemiologic variables of imported malaria cases were analysed.

Results: Malaria incidence in general reduced greatly in China, while the proportion of Plasmodium falciparum increased threefold from 0.08 to 0.21 per 100,000 population during the period 2010-2014. Of a total 17,725 malaria cases reported during the study period, 11,331 (64\%) were imported malaria and included an increasing trend: 292 (6\%), 2103 (63\%), 2151 (84\%), 3881 (96\%), 2904 (97\%), respectively, ( $\left.X^{2}=2110.70, p<0.01\right)$. The majority of malaria cases (imported and autochthonous) were adult (16,540, $93 \%)$, male (15,643, 88 \%), and farming as an occupation (11,808, $66 \%)$. Some 3027 (94\%) of imported malaria cases had labour-related travel history during the study period; 90 \% (6340/7034) of P. falciparum infections were imported into China from Africa, while 77 \% of Plasmodium vivax infections (2440/3183) originated from Asia.
\end{abstract}

Conclusions: Malaria elimination in China faces the challenge of imported malaria, especially imported P. falciparum. Malaria prevention activities should target exported labour groups given the increasing number of workers returning from overseas.

Keywords: Imported malaria, Surveillance, Elimination, Exported labour, China, Africa

\section{Background}

Malaria continues to be a major public health issue. The World Health Organization estimates that 198 million malaria cases and 584,000 malaria deaths occurred globally in 2014 [1]. The heaviest burden of malaria is in subSaharan Africa, which constitutes approximately $90 \%$ of total estimated malaria deaths. Historically, malaria was one of the most prevalent parasitic diseases in China.

\footnotetext{
*Correspondence: yuhj@chinacdc.cn; yangwz@chinacdc.cn †Sheng Zhou and Zhongjie Li contributed equally to this work ${ }^{1}$ Key Laboratory of Surveillance and Early-warning on Infectious Disease, Division of Infectious Disease, Chinese Centre for Disease Control and Prevention, 155 Changbai Road, Changping District, Beijing 102206, China

Full list of author information is available at the end of the article
}

Yet, after decades of control efforts, the malaria burden has been dramatically reduced from a peak malaria incidence of $2961 / 100,000$ population in 1970 to $0.1 / 100,000$ in 2014 [2-4]. The total population at risk in China is shrinking and since 2010 only Yunnan province reports autochthonous Plasmodium falciparum malaria. As a result of this progress, starting in 2010, the Chinese Government began implementing a malaria elimination plan to achieve malaria-free status by 2020 [5].

Plasmodium vivax has historically been the predominant Plasmodium species in China [2, 3]. The percentage of $P$. vivax varied from 80 to $95 \%$ of total malaria cases annually with the remaining percentage being $P$. falciparum. However, with a decrease in autochthonous malaria cases, the situation in China is changing and total 
falciparum malaria is increasing. Imported $P$. falciparum malaria cases have been reported recently in all provinces in China [6-8], which poses a major challenge due to its potential for fatal cases [9].

Another issue is the risk of malaria re-introduction due to importation, which has been identified in China and elsewhere, for example in Greece [10, 11]. The re-emergence of imported malaria in central China worsened between 2000 and 2009 as the total malaria incidence rate reached a peak of 5.9/100,000 population up from $1 / 100,000[12,13]$. Thus far the risk of imported malaria from other endemic settings continued to increase and this is a major challenge for malaria elimination in China. The objectives of the current study were to better understand and address this challenge, the epidemiological profile and trends of imported malaria in China from 2010 to 2014.

\section{Methods}

\section{Surveillance data}

Malaria has been a notifiable disease in China since 1956. Currently, over 68,000 health facilities report notifiable diseases to the national, real-time, internet-based disease reporting system, known as the China Information System for Disease Control and Prevention (CISDCP). One-hundred percent of the Centres for Disease Control and Prevention (CDC), $98 \%$ of hospitals above county level and $94 \%$ of hospitals below county level report to the CISDCP [14]. According to the Technical Scheme of Malaria Elimination in China [15], all positive blood smears and $10 \%$ of negative blood smears are checked by county CDC for quality assurance. The provincial CDC rechecked blood smears of all possible, probable and confirmed cases reported from counties with a malaria incidence rate lower than $1 / 10,000$ population annually over the past 3 years. A retrospective analysis using routine surveillance data from the CISDCP during the period of 2010-2014 was carried out. The basic malaria case information included: date of birth, gender, occupation, usual residence, details of malaria illness such as date of onset of symptoms, date of diagnosis, date of treatment, and method of diagnosis.

\section{Epidemiological data}

Additional epidemiological information was obtained from the Information System for Parasitic Disease Control and Prevention (ISPDCP), which is entered by the local county-level CDC after interviewing malaria patients once the county hospital submits a malaria case report to the national CISDCP system. A national case investigation form is used to collect additional epidemiological information, including details on travel history, such as date of departure from China, date of arrival back to China, countries visited, and purposes of travel. Based on this information, county-level CDC staff can determine if the malaria case is autochthonous or imported. For those with complete details, the epidemiological information is matched to surveillance data by a unique case reporting code. For those without complete case details, the data are matched by name, usual residence and household address.

\section{Malaria case definition}

Malaria cases with laboratory-confirmed Plasmodium infections notified to the CISDCP during 2010-2014 were included in the study. Laboratory confirmation denotes parasites in microscopic examination of a blood smear. Cases were classified as Chinese or foreigner. According to the Technical Scheme of Malaria Elimination [15], an imported case was defined as a malaria infection traced to an origin in a malaria-endemic area outside China and within 1 month after returning from the endemic area. An autochthonous case is defined as a malaria infection from local transmission with no history of travel and locally acquired transmission cannot be disproven.

\section{Inclusion and exclusion criteria}

All patients confirmed by microscopy and audited by the CISDCP from the period of January 2010 through December 2014 were included in this study. Probable and possible cases in the CISDCP were excluded from the study. Duplicate cases were excluded by identifying each condition of unique case reporting code, personal identification code, and patient's name plus current residence. Due to poor supporting information, relapse and recurrence cases were also excluded.

\section{Statistical analysis}

Descriptive statistics was done for all important variables. Year-on-year change was done for the distribution of imported malaria as well as falciparum malaria over the study period. The trends of this distribution was assessed with $\mathrm{X}^{2}$ for trend analysis test. Statistical significance was set at $5 \%$ level, unless otherwise stated. Data were analysed with Stata version 10.0 (Stata Corporation, College Station, TX, USA).

\section{Results}

\section{General surveillance}

Between 2010 and 2014, 17,725 malaria cases were diagnosed by microscopy; 17,079 (96 \%) cases were Chinese and 646 (4\%) were foreign nationals; 11,331 (64\%) imported malaria cases were reported with an increasing trend from 2010 to 2014 compared to the total: 292 (6\%), 2103 (63\%), 2151 (84 \%), 3881 (96\%), 2904 (97\%), 
respectively, $\left(\mathrm{X}^{2}=2110.70, \mathrm{p}<0.01\right)$ (Fig. 1). A total of $362(2 \%)$ autochthonous malaria cases were reported from 2011 to 2014 compared to the total: 18 (0.5\%), 199 (8\%), 83 (2\%), 62 (2\%), respectively, $\left(\mathrm{X}^{2}=8.76\right.$, $\mathrm{p}<0.01) ; 6032$ (34 \%) of reported malaria cases were without a known source of infection from 2010 to 2014: 4474 (94\%), 1233 (37\%), 218 (8 \%), 64 (2\%), 43 (1\%), respectively, $\left(\mathrm{X}^{2}=9456.50, \mathrm{p}<0.01\right)$. Total malaria incidence (per 100,000 population) in China had a general decreasing trend from 2010 to 2014: 0.55, 0.30, 0.18, 0.28, 0.21 respectively. A total of 98 deaths occurred during the period of 2010-2014: 15, 27, 15, 20, 21 respectively, $\left(\mathrm{X}^{2}=1887.74, \mathrm{p}<0.01\right)$.

\section{Characteristics of demographic and epidemiological distribution}

Between 2010 and 2014, altogether 17,725 malaria cases were reported. The median age of these cases was 37.2 years (range 37.0-37.4) and the majority was males $(15,643,88 \%)$ and farmers by occupation $(66 \%, 11,808)$ (Table 1). Sixty-nine percent $(12,253)$ of total autochthonous and imported malaria cases were reported in Anhui, Guangxi, Henan, Jiangsu, Sichuan, and Yunnan provinces. Total imported malaria cases were reported in 1499 (51 \%) counties from all 31 provinces in China (Fig. 2).

\section{Plasmodium species}

Of 17,278 cases with identified parasite species (97\% of total confirmed cases), P. falciparum accounted for $49 \%$ (8631) and P. falciparum incidence (per 100,000 population) between 2010 and 2014 was $0.08,0.10,0.10,0.21$, 0.13 respectively. The share of $P$. falciparum reached a high of $71 \%$ of the total in 2013, up from $24 \%$ in 2010. Among 11,331 total imported malaria cases from 2010 to 2014, P. falciparum was the highest at 7218 cases (64\%).

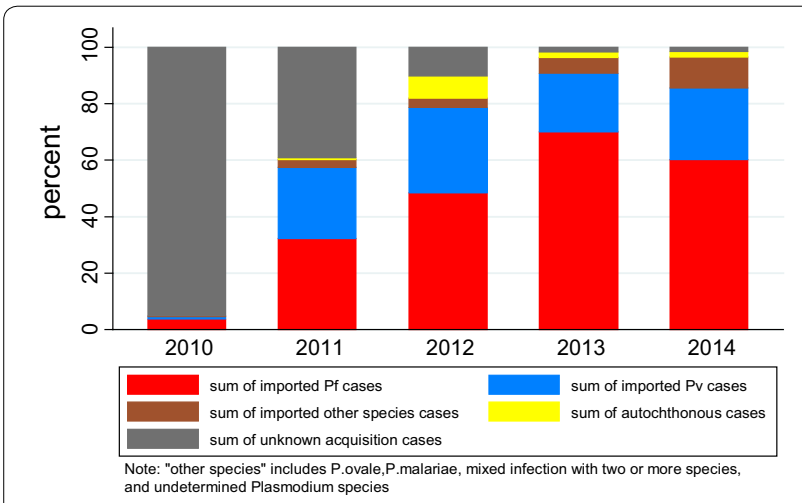

Fig. 1 Acquisition of malaria cases in China by species (2010-2014)
Plasmodium vivax accounted for $45 \%$ (7963) and the total share of $P$. vivax declined from 69 to $28 \%$ from 2010 to 2014. Among 11,331 total imported malaria cases from 2010 to 2014, P. vivax cases were 3346 (30\%).

Plasmodium ovale and Plasmodium malariae accounted for $2.7 \%$ (512) and all P. ovale and P. malariae cases were imported from 2010 to 2014. The percentage of $P$. ovale increased from 0 to $7 \%$, and the percentage of P. malariae increased from 0.02 to $2 \%$ from 2010 to 2014 . Mixed infections with two or more species accounted for $1 \%$ (171) and the majority (156) were imported cases. One imported case of Plasmodium knowlesi was identified, and 447 (3\%) malaria case species were unidentified.

\section{Characteristics of travel-related information}

In those 3220 (18\%) cases with known reasons for travelling, the vast majority $(3027,94 \%)$ was exported labour (i.e., working overseas) (Table 1). Among the 2124 cases (12\%) with available information on staying overseas: 98 (4.6\%) cases stayed less than 30 days, 468 (22.0\%) stayed less than 180 days, 754 (35.5\%) stayed less than 365 days, 804 (37.8 \%) stayed more than 365 days.

Study results show that of the 4310 imported malaria cases where complete patient information was captured, 321 (7\%) had malaria symptoms before their arrival in China after staying overseas, and 3378 (78 \%) had symptoms within 30 days after their arrival from staying overseas; 3004 (84\%) of imported P. falciparum cases and 227 (50\%) of imported $P$. vivax cases had malaria symptoms within 1 month of their arrival from staying overseas (Table 2).

\section{Region of infection acquisition}

Of the 11,331 imported malaria cases, $96 \%(10,925)$ had country information available on the location of suspected infection acquisition. Between 2010 and 2014, imported malaria case infections were acquired from 74 countries. Acquired infections were the highest among those travelling to Africa: 7679 (70 \%), second highest were from Asian countries with 3208 (29 \%) cases, 28 $(0.26 \%)$ were from Oceanic countries and ten $(0.09 \%)$ from South America. Malaria cases imported from Angola, Equatorial Guinea, Ghana, Myanmar, and Nigeria accounted for $66 \%$ (7255) of total imported cases from 2010 to 2014. Ninety percent (6340/7034) of falciparum malaria cases were acquired in Africa, whereas $77 \%$ of vivax (2440/3183) malaria cases originated from Asia (Table 3).

\section{Discussion}

Malaria incidence in China has been decreasing since 2010, and this study presented results on a changing malaria situation in China. Historically, $P$. vivax has been 
Table 1 Demographic characteristics of malaria cases in China, 2010-2014

\begin{tabular}{|c|c|c|c|c|c|c|c|c|c|c|c|}
\hline \multirow[t]{2}{*}{ Variable } & \multirow[t]{2}{*}{ Categories } & \multicolumn{2}{|l|}{2010} & \multicolumn{2}{|l|}{2011} & \multicolumn{2}{|l|}{2012} & \multicolumn{2}{|l|}{2013} & \multicolumn{2}{|l|}{2014} \\
\hline & & No. & $\%$ & No. & $\%$ & No. & $\%$ & No. & $\%$ & No. & $\%$ \\
\hline \multirow[t]{2}{*}{$\operatorname{Sex}(N=17,725)$} & Male & 3704 & 77.72 & 2873 & 85.66 & 2363 & 92.02 & 3847 & 95.51 & 2856 & 94.92 \\
\hline & Female & 1062 & 22.28 & 481 & 14.34 & 205 & 7.98 & 181 & 4.49 & 153 & 5.08 \\
\hline \multirow[t]{7}{*}{ Age $(\mathrm{N}=17,725)$} & $<10$ & 237 & 4.97 & 117 & 3.40 & 36 & 1.40 & 22 & 0.55 & 16 & 0.53 \\
\hline & $10-19$ & 365 & 7.66 & 147 & 4.38 & 106 & 4.13 & 92 & 2.28 & 47 & 1.56 \\
\hline & $20-29$ & 1014 & 21.28 & 799 & 23.82 & 593 & 23.09 & 928 & 23.04 & 656 & 21.80 \\
\hline & $30-39$ & 1121 & 23.52 & 870 & 25.94 & 738 & 28.74 & 1159 & 28.77 & 802 & 26.65 \\
\hline & $40-49$ & 1052 & 22.07 & 967 & 28.83 & 797 & 31.04 & 1415 & 35.13 & 1071 & 35.59 \\
\hline & $50-59$ & 464 & 9.74 & 248 & 7.39 & 243 & 9.46 & 378 & 9.38 & 372 & 12.36 \\
\hline & $\geq 60$ & 513 & 10.76 & 206 & 6.14 & 55 & 2.14 & 34 & 0.84 & 45 & 1.50 \\
\hline \multirow[t]{5}{*}{ Occupation ( $N=17,725)$} & Farmer & 2323 & 48.74 & 1643 & 48.99 & 1098 & 42.76 & 2207 & 54.79 & 1260 & 41.87 \\
\hline & Labourer & 1107 & 23.22 & 569 & 16.96 & 392 & 15.26 & 588 & 14.60 & 405 & 13.46 \\
\hline & Worker & 326 & 6.84 & 292 & 8.71 & 325 & 12.66 & 419 & 10.40 & 433 & 14.39 \\
\hline & Officer & 86 & 1.80 & 100 & 2.98 & 110 & 4.28 & 138 & 3.43 & 113 & 3.76 \\
\hline & Other & 924 & 19.39 & 750 & 22.36 & 643 & 25.03 & 676 & 16.78 & 798 & 26.52 \\
\hline \multirow[t]{5}{*}{ Purpose of travelling overseas $(n=3220$ ) } & Labour export & 29 & 74.36 & 347 & 91.80 & 446 & 91.21 & 1525 & 96.15 & 680 & 93.41 \\
\hline & Business trip & 1 & 2.56 & 9 & 2.38 & 7 & 1.43 & 18 & 1.13 & 11 & 1.51 \\
\hline & Tourism & 1 & 2.56 & 4 & 1.06 & 5 & 1.02 & 10 & 0.63 & 7 & 0.96 \\
\hline & Study & 4 & 10.26 & 2 & 0.53 & 9 & 1.84 & 8 & 0.50 & 0 & 0 \\
\hline & Other & 4 & 10.26 & 16 & 4.23 & 22 & 4.50 & 25 & 1.58 & 30 & 4.12 \\
\hline \multirow[t]{5}{*}{ Days staying overseas $(n=2124)$} & Days & & & & & & & & & & \\
\hline & $\leq 30$ & 6 & 6.59 & 17 & 11.72 & 18 & 7.17 & 30 & 2.36 & 27 & 7.34 \\
\hline & $31-180$ & 28 & 30.77 & 44 & 30.34 & 76 & 30.28 & 207 & 16.31 & 113 & 30.71 \\
\hline & $181-365$ & 25 & 27.47 & 40 & 27.59 & 69 & 27.49 & 516 & 40.66 & 104 & 28.26 \\
\hline & $\geq 366$ & 32 & 35.16 & 44 & 30.34 & 88 & 35.06 & 516 & 40.66 & 124 & 33.70 \\
\hline
\end{tabular}

the predominant Plasmodium species in China, varying from 77 to $94 \%$ annually between 2001 and 2009 . The relative proportions of falciparum and vivax malaria cases have reversed between 2010 and 2014, and currently $P$. falciparum is the predominant species of all malaria cases (autochthonous and imported) in China. The changing proportion of Plasmodium malaria has been mainly due to effective malaria control activities nationwide. Moreover, the total proportion of $P$. ovale and $P$. malariae cases increased during this period. As of 2014, the only remaining autochthonous malaria cases were identified in Yunnan and Tibet provinces, with Yunnan being the last stronghold for ongoing $P$. falciparum malaria transmission.

Imported malaria cases had different characteristics compared to autochthonous malaria cases. Autochthonous malaria cases were typically identified among all age groups, originated in specific endemic areas, and during clear seasonal peaks. Major characteristics of imported cases included being adult, male, and farming as an occupation with reported labour-related travel history to other countries. Additional characteristics of imported cases included being reported in the non-transmission season, and were distributed nationwide, even in the areas with no history of malaria transmission [16-19]. This is a challenge for passive surveillance systems in those counties or provinces currently without malaria transmission because of their poor capacity of case detection as total malaria incidence reduces to zero in many counties. Maintenance of case detection in certain health facilities should be a critical activity where surveillance was taken as one intervention during malaria elimination in China.

Between 2010 and 2014, imported P. falciparum was reported in all provinces in China, largely due to importation from other countries, especially from Africa where $P$. falciparum is the main parasite. This may be partly attributed to an increasing number of Chinese labourers who visit Africa given the recent cooperation between Africa and China. Tatem et al. indicated that certain countries in West African and Central Asia are more strongly connected by high levels of infection movement than others [20]. This study found that $94 \%$ of imported cases had recent labour-related travel history. Similarly, Liu et al. indicated that imported malaria cases in Jiangsu Province, China were mostly related to the export of labour 


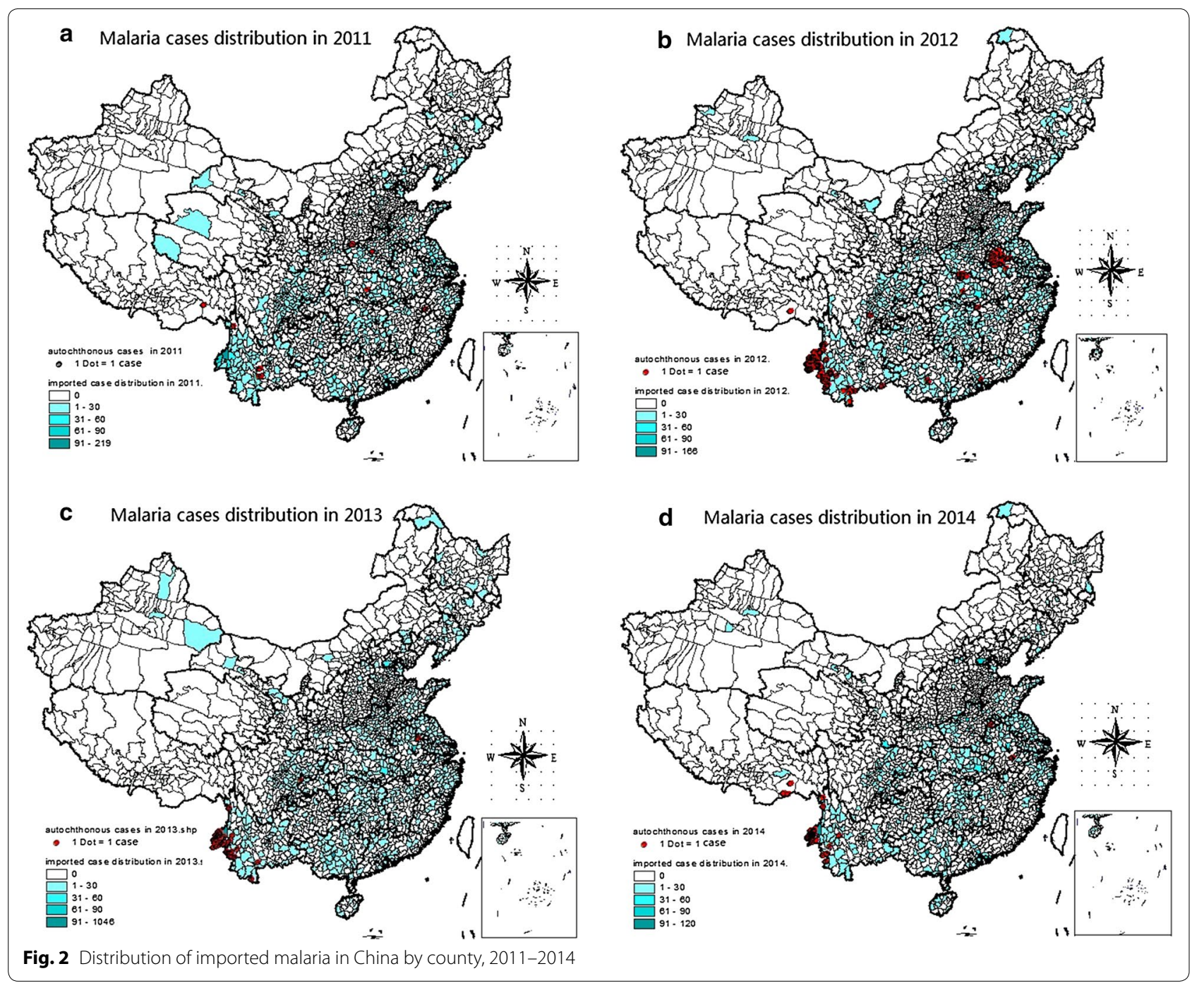

Table 2 Interval days from date of arrival to date of symptom onset in China during 2010-2014

\begin{tabular}{|c|c|c|c|c|c|c|c|c|}
\hline $\begin{array}{l}\text { Interval (days) } \\
(\mathrm{n}=4310)\end{array}$ & P. falciparum & $\%$ & P. vivax & $\%$ & Other Plasmodium ${ }^{a}$ & $\%$ & Total & $\%$ \\
\hline$\leq-1$ & 266 & 7.49 & 43 & 9.58 & 12 & 3.86 & 321 & 7.45 \\
\hline 0 & 263 & 7.41 & 14 & 3.12 & 15 & 4.82 & 292 & 6.77 \\
\hline $1-30$ & 2741 & 77.21 & 213 & 47.44 & 132 & 42.44 & 3086 & 71.60 \\
\hline $31-60$ & 195 & 5.49 & 70 & 15.59 & 50 & 16.08 & 315 & 7.31 \\
\hline $61-90$ & 43 & 1.21 & 36 & 8.02 & 21 & 6.75 & 100 & 2.32 \\
\hline$\geq 91$ & 42 & 1.19 & 73 & 16.26 & 81 & 26.04 & 196 & 4.55 \\
\hline
\end{tabular}

a Others including P. ovale, P. malariae, mixed infection with two or more species, and undetermined Plasmodium species

[21]. Statistics from the China Ministry of Commerce shows that legal export of labour overseas included approximately 800,000 individuals annually over the past 5 years and the number of export labourers continues to rise each year [22]. Given this trend, international population movement between China and other malariaendemic countries will be become even more frequent. The study findings presented the diversity of malaria importation from both African and Asian countries. Ninety percent of imported falciparum malaria came 
Table 3 Imported malaria country of acquisition in China during 2010-2014 by Plasmodium species

\begin{tabular}{|c|c|c|c|c|c|c|c|c|}
\hline $\begin{array}{l}\text { Country of acquisition } \\
(n=10,925)\end{array}$ & P. falciparum & $\%$ & P. vivax & $\%$ & $\begin{array}{l}\text { Other } \\
\text { Plasmodium }^{\mathrm{a}}\end{array}$ & $\%$ & Total & $\%$ \\
\hline \multicolumn{9}{|l|}{ Africa } \\
\hline Ghana & 1547 & 21.99 & 123 & 3.86 & 112 & 15.82 & 1782 & 16.31 \\
\hline Angola & 932 & 13.25 & 51 & 1.60 & 80 & 11.30 & 1063 & 9.73 \\
\hline Equatorial Guinea & 789 & 11.22 & 61 & 1.92 & 111 & 15.68 & 961 & 8.80 \\
\hline Nigeria & 800 & 11.37 & 60 & 1.89 & 76 & 10.73 & 936 & 8.57 \\
\hline Cameroon & 237 & 3.37 & 15 & 0.47 & 27 & 3.81 & 279 & 2.55 \\
\hline Congo & 197 & 2.80 & 12 & 0.38 & 22 & 3.11 & 231 & 2.11 \\
\hline Liberia & 168 & 2.39 & 25 & 0.79 & 26 & 3.67 & 219 & 2.00 \\
\hline Ethiopia & 39 & 0.55 & 167 & 5.25 & 7 & 1.00 & 213 & 1.95 \\
\hline Guinea & 136 & 1.93 & 9 & 0.28 & 15 & 2.12 & 160 & 1.46 \\
\hline Mozambique & 123 & 1.75 & 9 & 0.28 & 9 & 1.27 & 141 & 1.29 \\
\hline Sierra Leone & 121 & 1.72 & 9 & 0.28 & 11 & 1.55 & 141 & 1.29 \\
\hline CongoDR & 109 & 1.55 & 13 & 0.41 & 13 & 1.84 & 135 & 1.24 \\
\hline Other African countries & 1142 & 16.24 & 166 & 5.22 & 110 & 15.54 & 1418 & 12.98 \\
\hline \multicolumn{9}{|l|}{ Asia } \\
\hline Myanmar & 571 & 7.84 & 1893 & 59.47 & 49 & 6.92 & 2513 & 23.00 \\
\hline Indonesia & 57 & 0.80 & 177 & 5.56 & 25 & 3.53 & 259 & 2.37 \\
\hline Cambodia & 14 & 0.20 & 144 & 4.52 & 5 & 0.71 & 163 & 1.49 \\
\hline Laos PDR & 14 & 0.19 & 86 & 2.70 & 1 & 0.14 & 101 & 0.92 \\
\hline Pakistan & 5 & 0.07 & 67 & 2.10 & 3 & 0.42 & 75 & 0.69 \\
\hline India & 5 & 0.07 & 47 & 1.48 & 1 & 0.14 & 53 & 0.49 \\
\hline Other Asian countries & 14 & 0.20 & 26 & 0.82 & 4 & 0.56 & 44 & 0.40 \\
\hline Oceania & 10 & 0.14 & 18 & 0.57 & 0 & 0 & 28 & 0.26 \\
\hline South America & 4 & 0.06 & 5 & 0.16 & 1 & 0.14 & 10 & 0.09 \\
\hline
\end{tabular}

${ }^{a}$ Others including P. ovale, P. malariae, mixed infection with two or more species, and undetermined Plasmodium species

from African countries thereby increasing the chance of potentially fatal cases [9]. Intervention regarding malaria among this internationally moving population should be undertaken. Malaria intervention in the border areas should be strengthened.

Compared to those travelling for tourism or business, overseas labourers stayed for longer periods, which possibly contributed to an increased risk of contracting malaria. Study findings support the targeting of malaria prevention activities in these higher risk groups. To reduce the burden of imported malaria cases in Chinese workers coming from other countries after long stays, interventions should be specific Chinese export labourers. Within this high burden group, evidence has shown there is poor knowledge and awareness of malaria prevention methods [23, 24]. Chemoprophylaxis alone may not be a good choice due to poor understanding of benefit of taking prophylaxis and the potential negative side effects, such as resistance to anti-malarial drugs. Given the increase in numbers of overseas labourers, the supply of chemoprophylaxis in these groups would also be a challenge. Chinese export labourers work mostly in construction and mining activities, therefore, occupation-based vector control methods should be considered $[25,26]$, including specific behaviour change communication activities.

Furthermore, the seasonal distribution of imported malaria into China fluctuated very little. However, within four to 5 weeks, 874 imported malaria cases in 2013 were detected after 4052 Chinese gold miners returned to China after working in Ghana [27]. This event indicated that timely detection and removal of new infections is critical to prevent re-establishment of transmission [28].

This study's findings show that $15 \%$ of imported $P$. falciparum cases and $60 \%$ of imported $P$. vivax cases had symptoms more than 30 days after returning from abroad. On the one hand, it indicated the definition of imported malaria should be revised. During the malaria control phase, travel history within the previous month is an appropriate definition to determine imported malaria. However, in the malaria elimination phase, the definition of imported malaria must include up to 3 months of travel history. On the other hand, it also indicated those 
cases should be identified as early as possible by active case detection, including reactive case detection and proactive case detection [26].

To conduct effective surveillance in this malaria elimination setting, new strategies and activities are needed. Although total malaria incidence is decreasing in China, highly sensitive diagnostics (such as PCR/LAMP) that are field-friendly, as well as genotyping techniques, are needed to identify asymptomatic and sub-patent infections and to distinguish the origin of those infections [29]. With improved rapid reporting capacity and targeted active and passive surveillance activities, responding to imported cases should be greatly improved among the target population at risk after returning from malariaendemic countries [30, 31].

Study limitations should be mentioned. National surveillance data in China are routinely collected using standardized forms. However, some missing epidemiological data were identified in ISPDCP due to a loss-tofollow-up after treatment in the health facility. Since ISPDCP was established in late 2011, malaria case investigation data collected prior to this starting were subsequently added to the ISPDCP database. Therefore, data in 2010 and 2011 may not be a reliable source of autochthonous cases, especially in some geographic areas of China. For example, the rate of missing case classification of case investigation was $17 \%$ from 2011 to 2014 . However, the ISPDCP database is the best source for national level data in China and there is no evidence to suggest that malaria cases with missing travel history information were systematically different than those with complete reports. Further, this study presented data showing that the quality of the malaria case information captured in the surveillance system has improved over the study period. Both imported and autochthonous malaria cases may be underestimated in 2010 and 2011 due to misclassification bias. In those provinces that have eliminated falciparum malaria, the identification of the parasite may be easier once travel history to endemic areas is considered. However, China's border areas with Laos, Myanmar and Vietnam make it more difficult to ascertain imported malaria. For example, $74 \%$ of these cases reported in 2010 had an unknown origin of infection. Since China began to pursue malaria elimination in 2010, improvements to the epidemiological survey form have been made and information collection improved. New factors were included in the revised case investigation forms, namely the origin of infection. The missing rate of origin of infection improved since 2011 and was only $1 \%$ of the total in 2014. Another limitation was the result from current definition of case classification in China: $23 \%$ of total imported cases with missing infection locations were partly due to the definition.

\section{Conclusions}

Since the Action Plan for Malaria Elimination in China (2010-2020) was issued in 2010, malaria epidemiology in China has changed dramatically. In Yunnan and Tibet provinces, where both imported and autochthonous malaria exists, cross-border movement and malaria importation will continue to pose a challenge. A continuous influx of imported malaria infections increases the potential for malaria re-introduction to all receptive areas of China. For China to reach its goal of malaria elimination, it must target those populations that travel abroad for economic reasons with effective malaria prevention strategies.

\section{Authors' contributions}

HJY, WZY, ZJL, and SZ conceived the study. SZ and ZJL drafted the manuscript. CJZ, QZ and HZL contributed to data analysis. CC, SSZ and XNZ revised the manuscript. All authors contributed to writing the manuscript. All authors read and approved the final manuscript.

\section{Author details \\ 1 Key Laboratory of Surveillance and Early-warning on Infectious Disease, Division of Infectious Disease, Chinese Centre for Disease Control and Preven- tion, 155 Changbai Road, Changping District, Beijing 102206, China. ${ }^{2}$ Global Health Group, University of California, San Francisco, San Francisco, CA, USA. ${ }^{3}$ National Institute of Parasitic Diseases, Chinese Centre for Disease Control and Prevention, Shanghai 200025, China.}

\section{Acknowledgements}

The authors thank all the professional staff involved in malaria surveillance activities in China for their valuable support. The authors thank the Ministry of Science and Technology of China (2014BAl13B05) and the Ministry of Health of China (No. 201202006) for financial support.

\section{Competing interests}

The authors declares that they have no competing interests.

Received: 10 October 2015 Accepted: 10 January 2016

Published online: 25 January 2016

\section{References}

1. WHO. World Malaria Report 2014. Geneva: World Health Organization. Available at http://www.who.int/malaria/publications/ world_malaria_report_2014/en/.

2. Shang LY, Li GQ, Zheng B, Gu ZC, Tang LH, Gao Q, et al. Malaria. In: Tang $L H, X u L Q$, Chen YD, editors. Parasitic disease control and research in China. Beijing: Academic; 2010. p. 83-111.

3. Yin JH, Zhou SS, Xia ZG, Wang RB, Qian YJ, Yang WZ, et al. Historical patterns of malaria transmission in China. Adv Parasitol. 2014;86:1-19.

4. Yin JH, Yang MN, Zhou SS, Wang Y, Feng J, Xia ZG. Changing malaria transmission and implications in China towards National Malaria Elimination Programme between 2010 and 2012. PLoS One. 2013;8:e74228.

5. Ministry of Health of the People's Republic of China. Action Plan of China Malaria Elimination (2010-2020) (in Chinese). Available at. http://www. moh.gov.cn/mohbgt/s10788//201005/47529.shtml.webcite.

6. Feng J, Xia ZG, Vong S, Yang WZ, Zhou SS, Xiao N. Preparedness for malaria resurgence in China: case study on imported cases in 2000-2012. Adv Parasitol. 2014;86:231-65.

7. Xia ZG, Yang MN, Zhang SS, Feng XY. Epidemiological analysis of the imported malaria cases in China 2011 (in Chinese). Chin J Dis Control Prev. 2014;18:226-30.

8. Z Zhang Q, Lai SJ, Zheng CJ, Zhang HL, Zhou S, Hu WB, et al. The epidemiology of Plasmodium vivax and Plasmodium falciparum malaria in China, 2004-2012: from intensified control to elimination. Malar J. 2014;13:419. 
9. Schlagenhauf-Lawlor P, Arguin PM. Malaria death in travelers. In: Schlagenhauf-Lawlor P, editor. Travelers' malaria (2nd Edition). PMPH USA: Academic; 2008. p. 323-329.

10. Cohen JM, Smith DL, Cotter C, Ward A, Yamey G, Sabot OJ, et al. Malaria resurgence: a systematic review and assessment of its causes. Malar J. 2012;11:122.

11. Andriopoulos P, Economopoulou A, Spanakos G, Assimakopoulos G, et al. A local outbreak of autochthonous Plasmodium vivax malaria in Laconia, Greece-a re-emerging infection in the southern borders of Europe? Int Infect Dis. 2013;17:e125

12. Zhou SS, Wang Y, Tang LH. Malaria situation in the People's Republic of China in 2005. Zhongguo Ji Sheng Chong Xue Yu Ji Sheng Chong Bing Za Zhi. 2006:24:401-3.

13. Zhang HW, Liu Y, Zhang SS, Xu BL, Li WD, Tang JH, et al. Preparation of malaria resurgence in China: case study of vivax malaria re-emergence and outbreak in Huang-Huai Plain in 2006. Adv Parasitol. 2014;86:205.

14. Chinese Centre for Disease Control and Prevention. [Information System for Disease Control and Prevention (CISDCP) operated ten years in China] (in Chinese). Available at. http://www.chinacdc.cn/zxdt/201404/ t20140401_95050.htm.webcite.

15. Chinese Centre for Disease Control and Prevention. [Technical Scheme of China Malaria Elimination, 2011th edition] (in Chinese). Available at. http://www.chinacdc.cn/tzgg/201109/P020110906378403678170.doc. webcite.

16. Muentener P, Schlagenhauf $P$, Steffen R. Imported malaria (1985-95): trends and perspectives. Bull World Health Organ. 1999;77:560-6.

17. Smith AD, Bradley DJ, Smith V, Blaze M, Behrens RH, Chiodini PL, et al. Imported malaria and high risk groups: observational study using UK surveillance data 1987-2006. BMJ. 2008;337:a120.

18. Jelinek T, Schulte C, Behrens R, Grobusch MP, Coulaud JP, Bisoffi Z, et al. Imported Falciparum malaria in Europe: sentinel surveillance data from the European network on surveillance of imported infectious diseases. Clin Infect Dis. 2002;34:572-6.

19. Dharmawardena P, Premaratne RG, Gunasekera WM, Hewawitarane M, Mendis K, Fernando D. Characterization of imported malaria, the largest threat to sustained malaria elimination from Sri Lanka. Malar J. 2015;14:177.
20. Tatem AJ, Smith DL. International population movements and regional Plasmodium falciparum malaria elimination strategies. Proc Natl Acad Sci USA. 2010;107:12222-7.

21. Liu YB, Hsiang MS, Zhou HY, Wang WM, Cao YY, Gosling RD, et al. Malaria in overseas labourers returning to China: an analysis of imported malaria in Jiangsu Province, 2001-2011. Malar J. 2014;13:29.

22. National Bureau of Statistics of China. China statistical yearbook 2013. Beijing: China Statistics Press; 2013.

23. Zhang M, Liu ZY, He HT, Luo L, Wang SQ, Bu HL, et al. Knowledge, attitudes, and practices on malaria prevention among Chinese international travelers. J Travel Med. 2011;18:173-7.

24. Ye XG, Zhu GF, Ji YJ, Xu J, Shi Q. Investigation on knowledge of malaria among exit laborers at Anhui port (in Chinese). Chin Front Health Quar. 2014;137:154-7

25. Cotter C, Sturrock HJ, Hsiang MS, Liu J, Phillips AA, Hwang J, et al. The changing epidemiology of malaria elimination: new strategies for new challenges. Lancet. 2013;382:900-11.

26. Moonen B, Cohen JM, Snow RW, Slutsker L, Drakeley C, Smith DL, et al Operational strategies to achieve and maintain malaria elimination. Lancet. 2010;376:1592-603.

27. Li ZJ, Yang YC, Xiao N, Zhou S, Lin KM, Wang DQ, et al. Malaria imported from Ghana by returning gold miners, China, 2013. Emerg Infect Dis. 2015;21:864-7.

28. Crowell V, Hardy D, Briët O, Chitnis N, Maire N, Smith T. Can we depend on case management to prevent re-establishment of P. falciparum malaria, after local interruption of transmission? Epidemics. 2012:4:1-8.

29. Tietje K, Hawkins K, Clerk C, Ebels K, McGray S, Crudder C, et al. The essential role of infection-detection technologies for malaria elimination and eradication. Trends Parasitol. 2014;30:259-66.

30. Clements AC, Reid HL, Kelly GC, Hay SI. Further shrinking the malaria map: how can geospatial science help to achieve malaria elimination? Lancet Infect Dis. 2013;13:709-18.

31. Yang GJ, Tanner M, Utzinger J, Malone JB, Bergquist R, Chan EY, et al. Malaria surveillance-response strategies in different transmission zones of the People's Republic of China: preparing for climate change. Malar J. 2012;11:426.

\section{Submit your next manuscript to BioMed Central and we will help you at every step:}

- We accept pre-submission inquiries

- Our selector tool helps you to find the most relevant journal

- We provide round the clock customer support

- Convenient online submission

- Thorough peer review

- Inclusion in PubMed and all major indexing services

- Maximum visibility for your research

Submit your manuscript at www.biomedcentral.com/submit
() Biomed Central 